\section{DO SCORPIONS COMMIT SUICIDE?}

CORRESPONDENTS of NATURE have repeatedly raised the question whether there is any truth in the old legend that a scorpion, when placed within a ring of red-hot embers, will, after making futile efforts to pass the fiery circle, deliberately kill itself by inflicting a wound with a sting in its own head. Surgeon-General Bidie, of Madras (vol. xi. p. 29), Dr. Ailen Thomson (vol. xx. p. 577), and Mr. Gillman (vol. xx. p. 629), have answered the question in the affirmative. The other side has been taken by Mr. Hutchinson (vol. xxi. p. 226), Mr. Curran (vol. xxi. p. 325), and Mr. Lloyd Morgan (vol. xxvii. p. 3I3). Mr. Hutchinson maintained that the animals experimented on by $\mathrm{Mr}$. Gillman had died from excessive heat. To this Mr. Gillman replied, that the temperature in the centre of such a circle of glowing charcoal as he used does not exceed $50^{\circ} \mathrm{C}$

The subject has lately been thoroughly investigated by Mr. Alfred G. Bourne, Professor of Biology in the Presidency College, Madras; and the results of his observations have been set forth in a paper communicated to the Royal Society by Prof. Ray Lankester. Some of the details of his experiments are not very pleasant reading, but it must be remembered that the question is one of considerable importance, because, if it could be proved that the scorpion commits suicide, its impulse to do so would be, as Mr. Romanes has pointed out, "a unique case of an instinct detrimental alike to the individual and to the species:"

One of the arguments used to disprove the existence of the supposed instinct is, that it is physically impossible for a scorpion to sting itself in a vulnerable place. Mr. Bourne shows that this statement is inaccurate. If, he says, a dead scorpion be taken which is quite limp and not in a state of rigour, it will be easily seen that the last four segments of the tail are about the only portions of the body, whether on the dorsal or ventral surface, where a scorpion could not sting itself. Further, if two fighting scorpions be watched, it will be seen that the extent to which the sting can be moved about is perfectly wonderful. Moreover, he has noticed that, when the scorpion is placed in very unpleasant circumstances, it not unfrequently lashes its tail about and causes actual penetration of the sting. If, for instance, the rays of a burning-glass be concentrated on any part of the body, the scorpion brings its sting there, and tries to strike away the source of irritation. Occasionally its efforts become more and more frantic, and the point of the sting catches somewhere. The scorpion, however, does not die unless the heat is concentrated on the back. In that case it soon succumbs, even if the sting has been tied town or previously removed.

The most important of Mr. Bourne's propositions is that the poison of a scorpion is quite powerless to kill the same individual, or another individual of the same species, or even scorpions of other species. If this proposition is established, there can, of course, be no further controversy about the nratter. A priori, it is not improbable, for Sir Joseph Fayrer has shown that the cobra poison will not affect a cobra. Mr. Bourne frequently took a scorpion in his hand, and, holding the sting between a pair of forceps, pricked the scorpion with the sting and squeezed out its poison. There was a little bleeding from the wound, but in every case the scorpion lived for days. $\mathrm{He}$ also trived stinging one scorpion with another, using in the first instance specimens of the same species, then specimens of different species. Occasionally, he thinks, the stung individual became a trifle sluggish, but it never died from the sting. In order to make sure that his method of squeezing out the poison was perfectly effective, Mr. Bourne, after stinging a scorpion, sometimes continued to hold the sting, and, taking a cockroach, squeezed out into it some more of the poison. The cockroach in- variably became very sluggish at once, and died in an hour or so. He also used a large cricket, stinging it in the femur of the large hind-leg; that leg became paralysed. When the animal was stung in the same place on both sides, both the hind-legs became useless, and it crawled away on the two anterior pairs of legs. Stung in the thorax it became quite torpid; when placed on its back it was not able to turn over. After considerable search, Mr. Bourne procured some specimens of Thelyphonus, which he chose as being the nearest relatives of the scorpions. He stung these in his usual method, and in each case they died within six seconds. He then tried some spiders, and they died in a few minutes when well stung. The slower general action in cockroaches and crickets is probably, he supposes, to be explained by the very inefficient circulation of the blood in insects as compared with Arachnida.

In all cases of artificial stinging $\mathrm{Mr}$. Bourne took especial care to avoid mechanical injury to the nerve ganglia. And he tried puncture without the introduction of scorpion poison. Using large insects for this purpose, he obtained complete freedom from ill effects when using simple puncture, whereas the same species of insects when punctured with introduction of scorpion poison were instantly paralysed, and died in half an hour. He also procured two small shore crabs. One he punctured between two joints of the great chela of one side; several drops of blood exuded, but they coagulated, and the crab remained well. The second he stung in the same place with scorpion's sting, squeezing it to insure poisoning. The claw was immediately paralysed, and the crab gradually became torpid, and died in less than an hour.

When a number of scorpions are kept together in captivity, it is not difficult to induce a couple to fight. Mr. Bourne isolated such a couple, and they fought on and off for two days, during which time each repeatedly stung the other. On another occasion he separated two scorpions which had been fighting, and which had repeatedly stung one another. They lived perfectly well.

Apropos of Mr. Gillman's remarks about the actual temperature to which the scorpion is subjected in the "fiery circle," Mr. Bourne tried this experiment. He placed a scorpion and a cockcroach (for comparison) in an incubator with glass sides, and gave them a piece of wood to walk about upon, and gradually raised the temperature. At $40^{\circ} \mathrm{C}$. both seemed uncomfortable, and the cockroach performed a sort of licking action on all its legs and antennæ. At $45^{\circ} \mathrm{C}$. the scorpion became very sluggish, and at $50^{\circ} \mathrm{C}$. it was nearly dead. A large furious scorpion before the experiment, it now lay on its back and did not attempt to get up. Mr. Bourne took it out and gave it a cold bath, and put it in a cool earthenware vessel, and in the course of two hours it recovered. The cockroach was left in the incubator till the temperature reached $52^{\circ} \mathrm{C}$. When nearly dead, it was taken out, and very gradually recovered. To try the effect of a wet heat, a scorpion and a cockroach were placed in water at $43^{\cup} \mathrm{C}$, and they both died almost immediately, whereas they would both have lived in cold water for hours.

The inference drawn by $\mathrm{Mr}$, Bourne from his experiments is tbat scorpions do not commit suicide, and that when they die within a ring of fire, heat is the cause of death. After he had reached this conclusion he was told that according to some authorities inclosure in a circle of oil, or inclosure under an inverted tumbler, will cause a scorpion to kill itself. He accordingly placed a scorpion on a plate within a ring of cocoa-nut oil. It calmly walked through. He placed another scorpion on a plate, and round the edge a thick roll of rag dripping with kerosene oil. The animal walked out over the rag. When daubed with oil, it appeared uncomfortable, but did nothing remarkable. The experiment with an inverted tumbler was made, and gave the same negative result. 